\title{
Health-related lifestyle in HIV/AIDS patients: a hybrid concept analysis
}

\author{
Mehrnoosh Khoshtarash $^{1}$, Mansoureh Ashghali Farahani ${ }^{1}$, Armin Zareiyan ${ }^{2}$ \\ ${ }^{1}$ Nursing Care Research Center (NCRC), School of Nursing and Midwifery, Iran University of Medical Sciences, Tehran, Iran \\ ${ }^{2}$ Department of Public Health Nursing, Nursing Faculty, Aja University of Medical Sciences, Tehran, Iran
}

\begin{abstract}
Introduction: The concept of lifestyle is closely related to the concept of health. Several studies have been conducted on the dimensions of health-related lifestyle in patients living with human immunodeficiency virus/acquired immunodeficiency disease (HIV/AIDS), but none has comprehensively addressed it. This study is carried out for the purposes of defining and clarifying its concept in HIV/AIDS patients.

Material and methods: This study used a hybrid model of concept analysis comprising three phases; namely, a theoretical phase, field work phase, and a final analysis phase. To find relevant literature, an electronic search of valid databases was utilised using keywords related to the concept of healthrelated lifestyle. In the field work phase semi-structured interviews were performed with 12 people living with HIV/AIDS. The conventional content analysis was used in two theoretical and field work phases, and the results were combined in the final analysis phase.

Results: From the sum of 1362 gained titles in theoretical phase, 71 texts were analysed and five attributes were extracted, including physical health behaviours, social and recreational activities, sexuality and fertility health, health-centred care, and distress and coping. The most important consequence of a healthy lifestyle in literature review is enhanced physical and mental health. Working in the field phase added a social interactions category to the feature of the concept. In the third phase with the combination of the results of two phases, the final definition of the concept was presented.

Conclusions: Health-related lifestyle in HIV/AIDS patients is a set of behaviours that have different physio-psycho-social dimensions that people display in their individual and social lives, thereby providing their physical and mental health.
\end{abstract}

HIV AIDS Rev 2019; 18, 2: 120-130 DOI: https://doi.org/10.5114/hivar.2019.86376

Key words: lifestyle, HIV, AIDS, health behaviours.

\section{Introduction}

Although since the first pandemic of human immunodeficiency virus/acquired immunodeficiency disease (HIV/ AIDS) has been around for decades, it is still recognised as one of the most important infectious diseases in the world today [1]. The significance of the disease can be traced back

Address for correspondence: Mansoureh Ashghali Farahani, BSCN, MSCN, PhD, Associate Professor, Nursing Care Research Centre (NCRC), School of Nursing and Midwifery, Iran University of Medical Sciences, Rashid Yasemi St., Valiasr Ave., Tehran, Iran, phone: +98214365223, fax: +982188201978,

e-mail: farahani.ma@iums.ac.ir, m_negar110@yahoo.com to 76.3 million people and 35 million deaths since the onset of the epidemic. The data provided in 2017 also indicate 36.9 million people worldwide, 1.8 million new cases, and about 1 million deaths associated with the disease [2].

Although improvements have been made in the treatment of aids, the aids virus is still a public health problem worldwide. Prevention, early diagnosis, and serious treatment
Article history:

Received: 12.12 .2018

Received in revised form: 31.12 .2018

Accepted: 05.02.2019

Available online: 20.05 .2019
International Journal of HIV-Related Problem

HIV \& AIDS

R e vi e w 
of the disease are important aspects of care for affected people, with which nurses deal with these patients in all of these areas. In this regard, admission of lifestyle and new behaviours consistent with this disease is one of the major concerns that a nurse faces in caring for affected people [3].

Lifestyle is defined as all behaviours that are under the control of a person or affect the health of the individual and it includes all behaviours such as eating habits, sleep and rest, physical activity and exercise, weight control, immunisation against disease, stress adjustment, and the ability to use family and community support [4]. In other words, lifestyle is a normal and daily activity that people have accepted into their lives in an acceptable way so that these activities affect their health [5]. The concept of lifestyle is closely related to the concept of health [6], and today most health problems are related to lifestyle and changes in lifestyle [7]. The World Health Organisation (WHO) believes that changing lifestyle can be countered by many risk factors that are among the most important causes of mortality [8]. Therefore, one of the goals of the WHO by 2020 is to promote a healthy lifestyle in the community, according to which countries should put in place strategies that are effective in improving individual and social life [4].

Several quantitative and qualitative studies are conducted on the dimensions of care for HIV/AIDS patients and their life experiences, including patient compliance with antiretroviral therapy (ART), social stigma, nutrition, and the prevention of transmission of disease to others, especially in risk groups, have been conducted in the world, all of which are dimensions of lifestyle, but none has comprehensively addressed the health-related lifestyle of these individuals. Interestingly, in spite of the general definitions given in various texts of the word life style, lyons and he in various papers believe that until now a comprehensive and complete definition that contains all the hidden angles of this concept is not provided and, of course, is emphasised. It is not possible to do this except by considering the mental aspects of the concept and the exact understanding of the grounds upon which the lifestyle is formed $[9,10]$. Therefore, considering the high prevalence of AIDS and the importance of lifestyle in the management of people with this disease, proper understanding and accurate assessment of the concept of lifestyle and health behaviours in the formulation and implementation of health plans for prevention and the promotion of the health, care, and treatment of these people it is essential.

In this regard, the present study was conducted to analyse the health-related lifestyle (HRL) in people with HIV/ AIDS (PLWHA), based on the hybrid model. Using the hybrid method based on the literature review as well as the life experience of the participants in the field can provide more accurate information about the concepts. The hybrid model depicts a clear picture of concepts based on the context and specific situation and, in this respect, has superiority to other conceptual analysis methods [11].

This paper tries to answer the following questions by using the concept of hybrid analysis:
1. How is the health-related lifestyle of people living with HIV/AIDS defined in the literature, and what are the properties, antecedents, and the consequences of this concept?

2. What do people with HIV/AIDS define or experience in their health-related lifestyle?

\section{Material and methods}

In this study, the concept of HRL in PLWHA was analysed using a hybrid model. The model consists of three theoretical phase, field work, and final analysis.

\section{Theoretical phase}

The present study employed a systematised, evidencebased approach to search the literature. This method includes one or more characteristics of a systematic review, but does not claim to present the same results as a systematic review does [12]. In this phase, the databases of Medlib, Iran Medex, Magiran, Sid, Irandoc, Web of Science, Google Scholar, Cinahl, PubMed, Medline, Proquest, Ovid, Elsevier, and Wiley were searched by a combination of keywords (lifestyle, health-related lifestyle, HIV, AIDS, health behaviours, quality of life), both in English and Persian, without time limit, and up to the end of 2017. According to inclusion criteria, articles with full text in Persian or English, and referring to the definition, outcomes, features, and outcomes of the concept of HRL, were evaluated. Exclusion criteria included repetitive texts, book reviews, letters to the editor, and unrelated texts. Figure 1 shows the process of reviewing and selecting texts at the theoretical stage. As shown in the figure, after the removal of repetitive texts and then the evaluation of the abstract of the texts in terms of relation with the concept, the full text of the articles that were qualified and relevant to the concept was investigated. Accordingly, from 885 titles obtained in the initial search, 68 research articles and three dissertations entered the analysis stage. Among the texts, 15 cases were reported in Asia, 29 in the United States, 22 in Africa, and five in Europe. Table 1 presents an overview some of studies conducted on HRL in PLWHA.

To analyse the literature, the conventional content analysis method was used based on the model proposed by Graneheim and Lundman. The texts were carefully studied by the researcher as a unit of analysis several times and summarised by meaning units. Each sentence, phrase, and a word referring to the definition and dimensions of the HRL in people with HIV/AIDS were identified, and each was assigned a code. The codes were categorised by performing continuous comparisons in different categories and subcategories according to their repetition, differences, and similarities.

\section{Field work phase}

Field phase data were collected from 12 HIV/AIDS patients referring to the behavioural disease counselling 


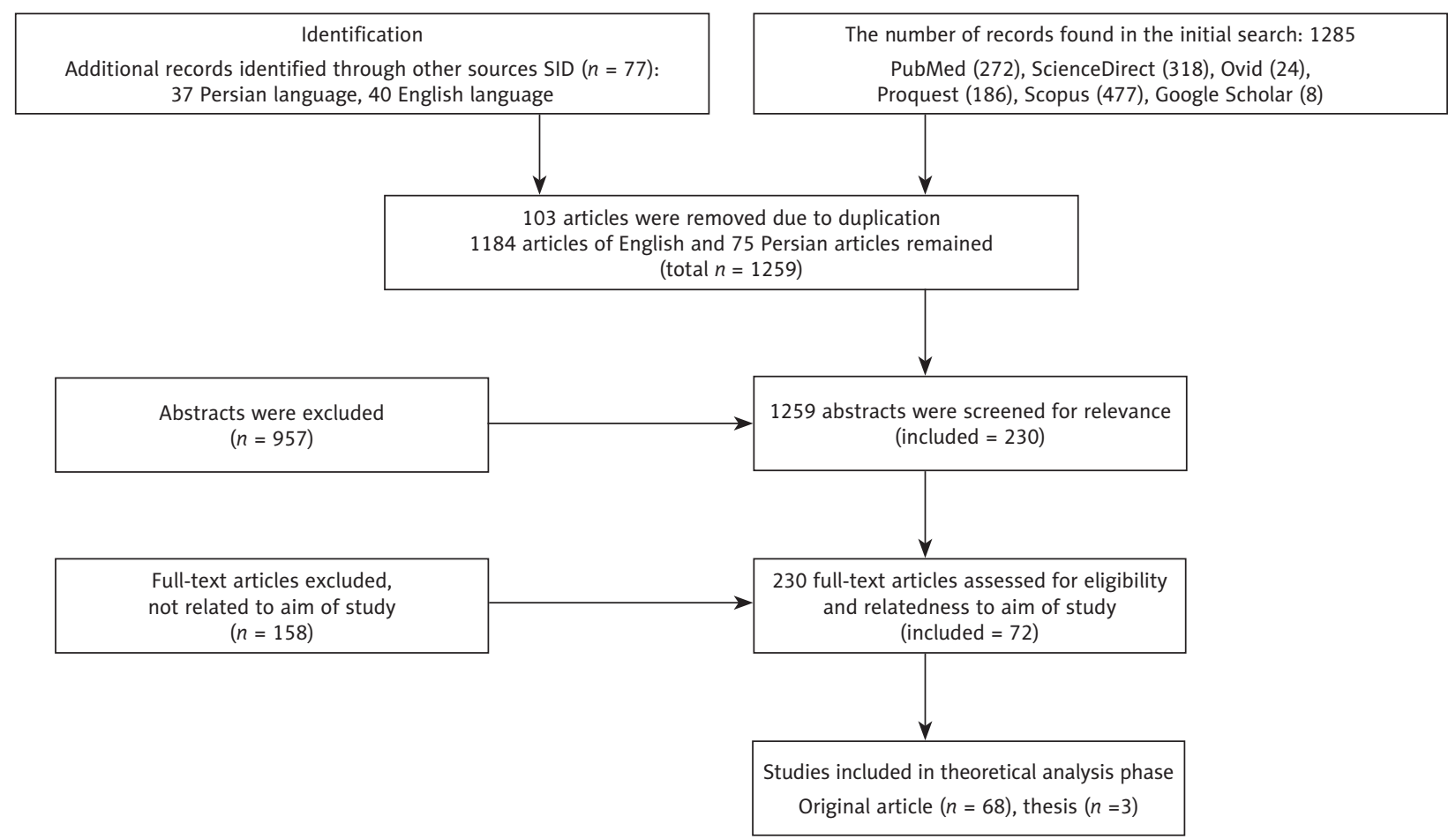

Figure 1. Summary of the theoretical phase based on the PRISMA flowchart (selection, critical appraisal, and data extraction of studies)

centres of Imam Khomeini Hospital (Tehran) and Rasht, from April to September 2018. In this phase, the views of PLWH on HRL were addressed. To select participants, a purposeful sampling approach was used, and attempts were made to comply with principles of maximum variation sampling. Participants with the ability to express their experiences in Persian and a willingness to participate in the study were included in the study. The general information of participants is presented in Table 2. In this phase, qualitative data were collected through individual, semi-structured, face to face, and thorough interviews by asking open questions and continuation until data saturation. Initially, the first interview was conducted by the first author (M.Kh.), and after having been approved by other members of the research team, the subsequent interviews were conducted. The interviews began with a broad and general question (for example: What do you normally do during the day?), and then exploratory questions were asked to encourage participants and gain more in-depth information (for example: How is your physical activity? What do you eat during the day? Explain your sleep situation). In other words, the following questions were asked based on the initial responses of the people and the interview guide. In the cases where the participant put forward a subject whose search was useful, the researcher also followed suit. The location and time of the interview were selected according to the opinion of the participants (usually in a private room in one of the counselling cen- tres mentioned above). The duration of the interview was between 35 and 80 minutes (average of 50 minutes), and all interviews were recorded. After transcribing 12 interviews, Maxqda10 Software (Udo Kuckartz, Berlin, Germany) was used to manage and organise the obtained data. For data analysis, directed content analysis method was used. First, the interviews were read word by word, line by line, and paragraph by paragraph several times in order to obtain the general understanding. Then, the meaning units and initial codes were extracted, and similar codes were classified as sub-categories. The related sub-categories formed categories, and the related categories formed the themes.

\section{Rigor of qualitative data in the field work phase}

To ensure the trustworthiness of qualitative data, the Lincoln and Guba criteria, including credibility, confirmability, dependability, and transferability, were used [13]. Member check (rechecking the meanings and codes of the interview with the participant) and peer check and external check (rechecking the meanings and codes of the interview with research colleagues as well as the four faculty members qualified in the qualitative research and research subject) prolonged engagement with the data gathering and analysing (allocating a lot of time to review and modify the codes several times), maximum variation during sampling, writing all 
Table 1. An overview of some of studies conducted on the concept of health-related lifestyle in people living with HIV

\begin{tabular}{|c|c|c|c|c|c|}
\hline Author (year) & Country & Study design & Study subject & Sample/sample size & Data collection \\
\hline Orban (2010) & USA & Cross-sectional & Coping strategies & $\begin{array}{l}166 \text { adolescents } \\
\text { with HIV/AIDS }\end{array}$ & Questionnaire \\
\hline Dessie (2012) & Africa & Qualitative & Sexual activities & 13 PLWHA & Interview \\
\hline Amoran (2012) & Nigeria & Cross-sectional & Risky sexual behaviours & 637 PLWHA & Questionnaire \\
\hline Saumoy (2016) & Spain & Clinical trial & $\begin{array}{l}\text { The impact } \\
\text { of multidimensional lifestyle } \\
\text { on cardiovascular risk factors }\end{array}$ & 54 PLWHA & $\begin{array}{l}\text { Questionnaire } \\
\text { and laboratory } \\
\text { tests }\end{array}$ \\
\hline Melchior (2007) & Brazil & Qualitative & ART adherence challenges & 34 PLWHA & Interview \\
\hline Nedjat (2015) & Iran & Mixed method & $\begin{array}{l}\text { Sexuality needs and fertility } \\
\text { health }\end{array}$ & $\begin{array}{l}40 \text { and } 400 \text { PLWHA } \\
\text { in qualitative and } \\
\text { quantitative study }\end{array}$ & $\begin{array}{l}\text { Interview and } \\
\text { questionnaire }\end{array}$ \\
\hline Nalugo (2015) & Uganda & Cross-sectional & $\begin{array}{l}\text { Lifestyle factors and fertility } \\
\text { health }\end{array}$ & $\begin{array}{l}614 \text { adolescents with } \\
\text { HIV/AIDS through } \\
\text { the prenatal }\end{array}$ & Questionnaire \\
\hline Uphold (2007) & USA & Cross-sectional & Healthy lifestyle and QoL & $\begin{array}{l}226 \text { males with } \\
\text { HIV/AIDS }\end{array}$ & Questionnaire \\
\hline Magidson (2015) & USA & Longitudinal & Structure of daily activities & 199 PLWHA & $\begin{array}{l}\text { Questionnaire } \\
\text { and electronic } \\
\text { monitoring }\end{array}$ \\
\hline Jorjani (2014) & Iran & Cross-sectional & $\begin{array}{l}\text { Disclosure and its related } \\
\text { factors }\end{array}$ & 175 PLWHA & Questionnaire \\
\hline Wang (2015) & China & Cross-sectional & $\begin{array}{l}\text { Changes in the use } \\
\text { of cigarettes after disease }\end{array}$ & 2973 PLWHA & Questionnaire \\
\hline Lee (2001) & USA & Cross-sectional & $\begin{array}{l}\text { Effect of sleep and activity } \\
\text { pattern on fatigue }\end{array}$ & $\begin{array}{c}100 \text { females with } \\
\text { HIV/AIDS }\end{array}$ & $\begin{array}{c}\text { Questionnaire } \\
\text { and electronic } \\
\text { monitoring }\end{array}$ \\
\hline Plach (2005) & USA & Qualitative & Self-care activities & $\begin{array}{l}9 \text { women } \geq 50 \text { years, } \\
\text { old with HIV/AIDS }\end{array}$ & Interview \\
\hline Ramirez (2004) & $\begin{array}{l}\text { Puerto } \\
\text { Rico }\end{array}$ & Cross-sectional & $\begin{array}{c}\text { Physical activity, leisure time, } \\
\text { life satisfaction }\end{array}$ & 67 PLWHA & Questionnaire \\
\hline Radfar (2014) & Iran & Qualitative & $\begin{array}{l}\text { Effective behaviours on } \\
\text { the transmission }\end{array}$ & 64 PLWHA & $\begin{array}{l}\text { Focus group } \\
\text { interview }\end{array}$ \\
\hline Moralejo (2006) & Spain & Cross-sectional & Art adherence & 143 PLWHA & Questionnaire \\
\hline Philogen (2014) & Haiti & Mixed method & $\begin{array}{c}\text { Complementary and } \\
\text { alternative medicine (CAM) }\end{array}$ & 680 PLWHA & $\begin{array}{l}\text { Questionnaire } \\
\text { and interview }\end{array}$ \\
\hline Abachi (2014) & Iran & Phenomenology & Stigma and QOL & 6 PLWHA & Interview \\
\hline Sowel (1997) & USA & Qualitative & Self-care activities & $\begin{array}{l}27 \text { females with } \\
\text { HIV/AIDS }\end{array}$ & $\begin{array}{l}\text { Focus group } \\
\text { interview }\end{array}$ \\
\hline Krishnan (2007) & India & Qualitative & Sexual activities & 30 PLWHA & Interview \\
\hline Sanders (2009) & USA & Qualitative & $\begin{array}{c}\text { Women sexual behaviours } \\
\text { and functions about } \\
\text { pregnancy }\end{array}$ & $\begin{array}{l}9 \text { mothers with } \\
\text { HIV/AIDS }\end{array}$ & Interview \\
\hline Rahmati (2009) & Iran & Qualitative & Risky behaviours & 61 PLWHA & Interview \\
\hline
\end{tabular}

the research steps explicitly so that other researchers would also be able to track the data, recording participants' statements, and a detailed description of the field and the participants were used to ensure the scientific accuracy and validity of the data collected at this stage.

\section{Final analytical phase}

In this phase, the codes and categories obtained from the field work phase were compared with the data obtained from the literature review in the theoretical phase, and final- 
Table 2. Demographic characteristics of the participants in the field work phase

\begin{tabular}{l|c|c|c|c|c|c|c|c}
\hline Participant & Gender & Age & $\begin{array}{c}\text { Marital } \\
\text { status }\end{array}$ & $\begin{array}{c}\text { Having } \\
\text { children }\end{array}$ & Education & $\begin{array}{c}\text { Duration } \\
\text { of disease }\end{array}$ & $\begin{array}{c}\text { Disease } \\
\text { situation }\end{array}$ & Transmission mode \\
\hline 1 & Male & $37 \mathrm{y}$ & Single & - & Middle school & $3 \mathrm{y}$ & AIDS & Jointly used needle syringe \\
\hline 2 & Male & $28 \mathrm{y}$ & Married & 1 child & Diploma & $7 \mathrm{y}$ & HIV & Jointly used needle \\
\hline 3 & Male & $39 \mathrm{y}$ & Single & - & Bachelor & $2 \mathrm{y}$ & HIV & Sex (homosexual) \\
\hline 4 & Male & $48 \mathrm{y}$ & Single & - & Diploma & $4 \mathrm{y}$ & HIV & Sex \\
\hline 5 & Male & $33 \mathrm{y}$ & Single & - & Diploma & $4 \mathrm{~m}$ & HIV & Sex \\
\hline 6 & Male & $37 \mathrm{y}$ & Married & No children & Diploma & $10 \mathrm{y}$ & AIDS & Jointly used needle \\
\hline 7 & Male & $25 \mathrm{y}$ & Single & - & Diploma & $3 \mathrm{y}$ & HIV & Sex \\
\hline 8 & Female & $40 \mathrm{y}$ & Married & 2 children & Bachelor & $2 \mathrm{y}$ & HIV & Unknown \\
\hline 10 & Female & $32 \mathrm{y}$ & Married & 1 child & Diploma & $2 \mathrm{y}$ & HIV & Unknown \\
\hline 11 & Female & $33 \mathrm{y}$ & Married & No children & Diploma & $2 \mathrm{y}$ & HIV & Probably dentistry \\
\hline 12 & Female & $38 \mathrm{y}$ & Married & 1 child & Middle school & $5 \mathrm{y}$ & HIV & Tattoos \\
\hline
\end{tabular}

ly the common features of HRL in HIV/AIDS patients were identified and the definition of the concept was presented.

\section{Ethical considerations}

Permission for this study was obtained from the Ethics Committee of Iran University of Medical Sciences (ethical approval number IR.IUMS.FMD.REC.1395.9221199206). Oral and written informed consent was received from the participants. The participants were allowed to leave the study at any time. All participants were assured that interviews would be completely confidential and that the results would be reported anonymously.

\section{Results}

\section{Theoretical phase}

In this section, the findings from the literature review are discussed in three parts: attributes, antecedents, and consequences.

\section{Attributes}

In the literature review, five main attributes were extracted (a total of 138 codes, 23 subcategories, 10 categories, and five main categories), which are referred to in the following:

1. Physical health behaviours: this category, which includes nutrition habits, physical activity, and sleep patterns, reflects the behaviours that people display in their daily lives in relation to their physical health. In a review of the literature, PLWHA compliance with the correct food pattern (healthy, fresh, and varied diet), having proper physical activity, particularly regular exercise, and improving sleep quality will help them to improve their health [14-17].
2. Social and recreational activities: interpersonal relationships and economic and social wellbeing are two important parts of this category. In general, the relationships that PLWHA have with their spouse/partner, family, friends, health professionals/health care providers, and the community, as well as disclosure or concealment of these people, are the main themes of interpersonal relationships. Socioeconomic prosperity includes issues related to individuals' occupational and recreational activities [18]. Unemployment, which mainly results from stigma and physical loss, can lead to loss of income and reduced welfare.

3. Sexuality and fertility health: sexual desire and activity $[19,20]$, giving information about sexual relations [21], sexual risk behaviours (non-use of a condom, having more than one partner, sexual relations with sex workers, unprotected anal sex, concurrent sexual relations, having IV drug-abusing partners, and lack of knowledge about partner's status) [21-26], attention to reproductive health (using family planning methods, pregnancy experience after diagnosis, and receiving prenatal care) $[19,21,27]$, and screening (performing pap smear and sexually transmitted disease testing) are the most important behaviours in this category of HRL mentioned in the literature review $[18,19]$.

4. Health-centred care: treatment adherence and self-care constitute two main dimensions of this category. Treatment adherence, which includes the strict implementation of the drug program and the ongoing follow-up of the disease (regular visits to the doctor and seeking medical care) in the review of the literature is an important part of PLWHA's lifestyle and is affected by a variety of factors [14, 28-31]. Self-care refers to activities that individuals carry out through their own abilities and resources aimed at promoting health and preventing dis- 
ease severity, including information about the disease, avoiding high-risk health behaviours (smoking, drug abuse, alcohol abuse), and the use of complementary and alternative medicine (CAM) [32-34].

5. Distress and coping: the last category of attributes of the concept of HRL in PLWHA, which was found in the literature review, was distress and coping. The stresses that individuals face due to the disease (psychosocial stress and treatment-related stress) and coping with those stresses are the main themes of this category. People with HIV/AIDS are exposed to various stresses $[35,36]$, and they use adaptive and maladaptive strategies to manage these stresses [37-41].

\section{Antecedents}

Health-related lifestyle antecedents referred to in the literature review can be divided into five categories:

1. Demographic factors: these factors include age, sex, education, place of residence, economic status, and occupational status. For example, age is among the antecedents influencing art adherence $[31,42]$, drug dependence [43], smoking [44], use of condoms in sexual relationships [26], and disclosure of illness [45].

2. Psychosocial factors: stigma, discrimination within the family, social, and health care settings, psychological disorders such as anxiety and depression, fear, social support, functional support, and moral responsibility are among factors that fall into this category. Stigma can be considered as the most important predictor, referred to in various texts, which influences on behaviours such as decrease of ART adherence [28, 39], reduction of interpersonal relationships $[29,46]$, nonuse of condoms [47], non-disclosure of disease [39, 48-50], suicidal ideation and action [49], and unprotected sex [51].

3. Clinical antecedents: modes of transmission, disease stage, number of symptoms, CD4 count, viral load, and the presence of symptoms such as pain and fatigue are antecedents that affect the HRL in PLWHA.

4. Health care system factors: the quality and quantity of physician-patient communication and antiretroviral drug-use factors can be found in this class of antecedents. A good relationship between physician and patient increases ART adherence [52], while difficult access to a doctor reduces it [53]. Drug-related factors also include the experience of side effects of medications $[28,47]$ or the concern about their experience $[36,53]$, intolerance, or drug tiredness $[28,53]$, difficult process of providing drug, and lack of trust in the medication [53].

5. Factors related to knowledge and attitude: lack of education and incorrect mental beliefs are the two main factors that fall into this category of antecedents. For example, in women with HIV/AIDS who did not have a Pap smear, lack of instruction by health care personnel and no obligation to perform this test because of difficulty were the two main reasons [54].

\section{Consequences}

As mentioned in the literature, the most important consequence of a healthy lifestyle is enhanced physical and mental health. Adopting a healthy lifestyle improves neurocognitive function, life quality, and satisfaction, and ultimately improves the physical and mental health of affected individuals $[14,15,34]$.

\section{Working definition}

HRL in PLWHA is a set of behaviours affected by various personal and social factors aimed at providing physical and mental health, including addressing physical health, health-centred care, sexuality and reproductive health, social and recreational activities, and stress management.

\section{Field work phase}

Six categories related to the concept of HRL were determined during interviews (Table 3), including:

- Physical health: eating habits, physical activity, and sleep are the three main parts of this category of lifestyle behaviours. A number of participants stated that they had been trying to improve their nutritional status and ultimately their physical health with healthy and diverse foods since they were infected: "I eat less sweets, but I always have my diary and milk. I try to eat every kind of food. I try to have every type of food such as proteins in my diet based on my medications". (p3)

Nightmares caused by ART were among the most important problems affecting sleep quality of participants: "At first when I took my medicines, I had nightmares as I was falling from somewhere or they were taking me to jail, I had horrible nightmares". (p5)

Physical weakness and loss of physical strength were problems that reduced the individuals' physical activity. In this regard, a participant reported: "I feel my body is debilitating, I'm not as strong as before, I feel like resting more". (p6)

- Social interactions: in relation to this category, one of the most important challenges that participants are faced with is the fear of exposing the disease and others' reaction to their disease, so that in some cases they went to another city or place to receive care in spite of the presence of health care services in their place of residence. In this regard, participant 4 stated: "In my family, only my brother knows it, I could tell no one then I wouldn't take my files from health care centre in county and come here to spend this much. No one can understand it".

Most participants expressed a number of instances in which they were treated in a discriminatory way in medication areas, or were even refused services: "Once I had a problem with my tooth and I went to two dentists, but they didn't accept me, at last I had to tell nothing in the third place to have my tooth treated". (p2)

Another participate reported: "Some time ago I had an accident, my uncle told the hospital staff about my dis- 
Table 3. Attributes extracted from fieldwork phase

\begin{tabular}{|c|}
\hline Main categories/Categories/Subcategories \\
\hline Physical health \\
\hline Nutritional habits \\
\hline Eating level \\
\hline Diversity of food \\
\hline Choose a healthy diet \\
\hline Sleep status \\
\hline Sleep quality \\
\hline Sleep schedule \\
\hline Physical activity \\
\hline Physical power \\
\hline Physical activity level \\
\hline Social interactions \\
\hline Disclosure of disease \\
\hline Disclosure to important people of life \\
\hline Disclosure to social and therapeutic centres \\
\hline Facing the challenges of disclosure \\
\hline Social support \\
\hline Interruptions in interpersonal relationships \\
\hline Relations with peers \\
\hline Being accepted \\
\hline General acceptance \\
\hline Acceptance by health care services \\
\hline Entertainment and welfare \\
\hline Recreational activities \\
\hline Physical-recreational activity \\
\hline Self-entertainment \\
\hline Communicating with others \\
\hline Financial problems \\
\hline Job instability \\
\hline Financial burden of disease \\
\hline
\end{tabular}

ease so that they can provide better care.... They didn't even visit me until 2 a.m., they didn't even touch me". (p11)

- Entertainment and welfare: the most important problem PLWHA are faced with in this area is economic problems. Reduced physical activity, avoidance of employers from employing affected people, and inappropriate co-workers' behaviours were among the most important issues that participants reported: "In the past, I had power of two healthy men, I could work but now I can't. This disease crippled me somehow ... then again if others know that they would not accept to work with me". (p1)

- Sexuality and fertility health: the main themes of this category are marriage, sexual relations, and childbearing. Constraints on establishing a family are another social consequence of the disease that were reported by
Table 3. Cont.

\begin{tabular}{|c|}
\hline Main categories/Categories/Subcategories \\
\hline Sexuality and fertility health \\
\hline Sexual activity \\
\hline Risky sexual behaviours \\
\hline Qualitative and quantitative sexual dysfunction \\
\hline Stressful marriage \\
\hline Unstable marriage \\
\hline Marriage rearrangement \\
\hline Childbearing \\
\hline Concerning about reproduction \\
\hline Getting advice \\
\hline Health-centred care \\
\hline Art adherence \\
\hline Proper implementation of ART program \\
\hline ART adherence challenges \\
\hline Self-care \\
\hline Continuous follow-up \\
\hline Preventive measures \\
\hline Seeking information \\
\hline Health-related risk behaviours \\
\hline Using complementary and alternative medicine \\
\hline Distress and coping \\
\hline Stress management \\
\hline Adaptive coping \\
\hline Maladaptive coping \\
\hline Reaction to limitations \\
\hline Fear of disease transmission \\
\hline Feeling of being limited \\
\hline
\end{tabular}

the majority of patients, especially those who were not married: "I thought there are some people like me who may intend to marry, but each person I dated told me that you yourself are sick. That's why I'm disappointed". (p1)

Regarding sexual activity, one of the participants stated: "My sexual relationship became less frequent, I always hated condoms, I'm not comfortable with it at all, I'm tolerating somehow...". (p11)

Most married patients who did not have a child and even some single patients reported one of their concerns was having a child: "I myself am much interested in having a baby but my husband doesn't accept it, early in my marriage I become pregnant but he took the official letter for getting an abortion, so I aborted my child". (p10)

- Health-centred care: adherence to ART and self-care constitute the main dimensions of this category of attributes. Regarding familiarity with drugs and their timely use, a participant stated: "I don't still know my medicine, 
I don't every take them on time, whenever I go to a party or somewhere, I took my mom's pills box and put them in it”. (p11)

A number of participants also said that they have become more sensitive to health since they were infected: "When something is harmful for me I don't consume it, if someone has cold I would not accept to drink water with his/her glass at all". (p6)

- Distress and coping: the strategies used by individuals to adapt to the disease constitute the main theme of this category. A number of people used positive methods (adaptive coping) and a number of negative methods (maladaptive coping) in adapting to the disease. In this regard, participant 9 stated: "At first I was deeply depressed, but little by little I get to know my disease, my husband helped me a lot, my family helped me a lot, they tried to keep me happy, I talked with god a lot, I was going to holy places every week".

\section{Discussion}

In this study, the concept of HRL in clinical nurses was investigated using a hybrid concept analysis approach by integrating the findings of theoretical and fieldwork phases. The results showed that health-related lifestyle is a complex and multidimensional pattern of a set of behaviours that PLWHA display in their daily lives to reduce their disease-related harm and increase their health. In the current study, six attributes were extracted as follows:

One of the extracted attributes was "addressing physical health", which includes dietary habits, sleep status, and physical activity. The findings of this study showed that most participants experienced problems such as lack of exercise and weight loss, physical weakness and loss of physical strength, and reduced sleep quality. These people believed that HIV/ AIDS had a negative impact on their physical condition, and because they were more susceptible to disease than ordinary people, they tried to follow a healthy diet, have enough rest, and do activities such as walking regularly to improve their physical health; in other words, they believed that the disease caused them to carefully monitor their physical condition and choose a healthier lifestyle. This was so serious that, according to some, they were somehow obsessed with their physical health.

The second attribute was "social interactions". In addition to living with chronic and threatening AIDS, patients face numerous challenges in their personal relationships with family, friends, colleagues, and even health care providers [55], and the everyday experience of social labelling and social exclusion is from the life experience of these people [18]. One of the most important challenges participants were faced with in social interactions was the fear of exposing the disease and the reactions of others to the disease. The importance of this issue is so high that some of the participants did not disclose their illness to any of their family members and, in some cases, they had migrated from their place of living due to the fear of disclosure and rejection.
However, families are the most important source of personal care during illness in many developing countries. AIDS has challenged this issue in many cases, and people with disabilities have been excluded from their families [56]. In other words, an individual with HIV/AIDS always finds himself/herself in a tense state of concealment and disclosure for help, and this disruptive situation deprives him/her of the role of a patient who could receive others' attention and empathy [46]. In the study by Esmaelzadeh et al., fear of being rejected by family and partner, as well as stigma and discrimination in the community, were factors that influenced the disclosure of the disease [57].

The social relationships of PLWHA are affected at different levels and with different dimensions and intensity. Many participants severely restricted their social circle, and in some cases they isolated themselves. In a study by Zhang et al., half of the people reported that the disease had influenced their individual relationships with relatives or friends [58]. In a study by Lekganyane et al., PLWHA also isolated themselves and took on hidden strategies [59].

In the field of social interactions, another issue that participants report is the need for community acceptance, particularly in health care systems. Many people complained about the inappropriate and discriminatory behaviour of health care providers and had even been refused by them. In the study by Tavakol and Nikain, most patients expressed annoyance and discomfort due to discriminatory treatment from physicians and unequal access to health care services [60].

The third feature of the concept of HRL in PLWHA is the issue of "entertainment and welfare" for these people. Job destabilisation due to reduced physical capacity, employers' refusal to employ them, and inappropriate co-worker encounters, and thus economic problems, were the most important concerns that participants in this area are faced with. Despite the fact that the HIV virus cannot be transmitted in most work environments or in normal working relationships, assuming the risk of transmission has led many employers to avoid employing sick people or to dismiss them. In most workplaces, affected people also encounter labels, insults, and exclusion from their colleagues [61]. In a study by Kabbash et al., PLWHA reported changes in their job status, inability to perform the job and similar activities the same as before being inflicted with the disease, lack of job opportunities, and lack of opportunities for recreational activities. Most patients had financial problems and feared that they would not have enough nutrition and care in the future [62].

"Sexuality and fertility health" was the fourth attribute derived from theoretical and field work data. In this study, sexual activity, married life, and reproduction of PLWHA were affected by the disease. Most participants reported decreased sexual intercourse or discomfort with condom use. In the study by Behboodi-Moghadam et al., HIV/AIDS also affected the physical ability for sexual intercourse, attitudes towards sex, and the quality of sex [63]. Another problem for the participants was the marriage issue. A number of them suggested that the disease is a major obstacle to their marriage. This issue was also reported in Fallahi's study [49]. 
The fifth attribute was "health-centred care". Adherence to ART was the most important aspect of this category of attributes. Although most participants stated that they were taking their medicines in a timely manner, almost all of them experienced adverse drug reactions and reported these side effects as well as the fact that the use of these drugs for their whole life was exhausting and debilitating. Drug use, even if it has no side effects, is reminiscent of the fact that the person is ill, and this can be regarded as a source of stress for the individual [49]. In a study by Li et al., a number of participants introduced drug tiredness or avoidance of drug side effects due to ART non-adherence [53]. PLWHA used strategies such as smoking cessation, drugs, and alcohol, giving information about the disease, and continuous follow-up to reduce the health effects of illness. In a study by Plach et al. and Sowel et al., PLWHA used some strategies to improve their physical and mental state $[38,40]$.

The last attribute was "distress and coping". Yang et al. argue that the main problem for HIV/AIDS patients is psychosocial problems, and the factors that are associated with this problem include adjustment in relation to occupation and profession, and economic, cultural, and psychological status [64]. In the present study, all participants experienced anxiety, misery, depression, disappointment, anger, and feelings of disability and incapability, and most of them experienced suicidal tendencies. These patients use adaptive strategies (such as trusting in God, changing attitudes toward disease and positive thinking, and referring to a psychologist) and maladaptive strategies (such as self-blaming, crying, silence, isolation, self-mutilation, and suicide) to adapt to the disease. Radzniwan et al. reported prevalence of depression, anxiety, and stress in their study of $36.9 \%, 45.1 \%$, and $26.7 \%$, respectively [65].

\section{Conclusions}

By applying the hybrid model, we analysed the concept of HRL of PLWHA in Iran, because no studies on this topic had been conducted in the past. In conclusion, according to the results of the theoretical and fieldwork phases of this study, HRL from the perspective of PLWHA is a set of behaviours that have different physio-psycho-social dimensions that people display in their individual and social lives, thereby providing their physical and mental health and adapting to the problems associated with the disease. In this regard, they are faced with many challenges.

The results of this study can lead to a clear definition of the concept of HRL in PLWHA based on the social and cultural characteristics of Iranian community and development of a valid and reliable tool for measuring the healthrelated lifestyle in these individuals, which can be applied by doctors, nurses, and sociologists. It is also possible to compare the tools of this study with existing lifestyle tools to reveal differences between the general tools in normal lifestyle and the specific tools employed by people living with HIV/AIDS.

\section{Limitations}

One limitation of this study was the lack of access to the full text copies of some papers. In addition, access to all resources via an electronic database was not possible. Another limitation was the language barrier and the use of literature just in English and Persian languages. Although in the hybrid concept development, the aim of the fieldwork phase is to empirically elucidate and explore the concept not its empirical generalisation, HRL in PLWHA is a context-based concept that needs to be studied from the perspectives of diverse cultures and contexts in order to provide a comprehensive definition.

\section{Acknowledgments}

This paper is a report of the qualitative part of a mixed method study conducted in Iran University of Medical Sciences for a nursing PhD degree. The authors would like to acknowledge all those who cooperated in the research project, especially the PLWHA, who kindly participated in the interviews and stated their valuable perceptions. This research was supported by the School of Nursing and Midwifery affiliated with Iran University of Medical Sciences.

\section{Conflict of interest}

The authors declare no potential conflicts of interest with respect to the research, authorship, and/or publication of this article.

\section{References}

1. Baryamutuma R, Baingana F. Sexual, reproductive health needs and rights of young people with perinatally acquired HIV in Uganda. Afr Health Sci 2011; 11: 211-218.

2. Global HIV \& AIDS statistics - 2018 fact sheet. UNAIDS, 2018. Available at: www.unaids.org/en/resources/fact-sheet.

3. Smeltzer S, Bare B, Hinkle J, Cheever K. Brunner and Suddarth's Textbook of Medical-Surgical Nursing. Lippincott Williams \& Wilkins, Philadelphia 2013.

4. Monahan FD, et al. Phipps' medical-surgical nursing: health and illness perspectives. Elsevier Mosby, 2007.

5. Gnardellis C, Tzamalouka G, Papadakaki M, et al. An investigation of the effect of sleepiness, drowsy driving, and lifestyle on vehicle crashes. Transportation research part F 2008; 11: 270-281.

6. Kožuchová M, Bašková M. Selected factors of lifestyle in relation to overweight in population of school-aged youth. Kontakt 2015; 17: e142-e146.

7. Moer M. Evidence of the effectiveness of intervention for secondary prevention and treatment of coronary heart. Dissertation, 2002.

8. Naghibi F, Golmakani N, Esmaily H, Moharari F. The relationship between life style and the health related quality of life among the girl students of high schools in Mashhad, 2012-2013. Iranian Journal of Obstetrics, Gynecology and Infertility 2013; 16: 9-19.

9. He K, Kramer E, Houser RF, et al. Defining and understanding healthy lifestyles choices for adolescents. J Adolesc Health 2004; 35: 26-33.

10. Lyons RF. Health lifestyle: out of style. Shift 2000; 3: 4.

11. Rafii F, Sajadi Hezaveh M, Seyed Fatemi N, Rezaei M. Concept Analysis of Social Support of New Graduate Nurses in the workplace: A Hybrid Model. Iran Journal of Nursing 2014; 26: 71-89. 
12. Grant MJ, Booth A. A typology of reviews: an analysis of 14 review types and associated methodologies. Health Info Libr J 2009; 26 : 91-108.

13. Speziale HS, Streubert HJ, Carpenter DR. Qualitative research in nursing: Advancing the humanistic imperative. Lippincott Williams \& Wilkins, 2011.

14. Fazeli PL, Woods SP, Heaton RK, et al. An active lifestyle is associated with better neurocognitive functioning in adults living with HIV infection. J Neurovirol 2014; 20: 233-242.

15. Saumoy M, Alonso-Villaverde C, Navarro A, et al. Randomized trial of a multidisciplinary lifestyle intervention in HIV-infected patients with moderate-high cardiovascular risk. Atherosclerosis 2016; 246: 301-308.

16. Lal LS, Grimes RM, Swint JM, Risser J. A retrospective study to determine the impact of medical-and lifestyle-based contraindications to a prescribed HAART regimen on clinical outcomes and adherence. J Clin Pharm Ther 2006; 31: 429-439.

17. Ramírez-Marrero FA, Smith BA, Meléndez-Brau N, et al. Physical and leisure activity, body composition, and life satisfaction in HIV-positive Hispanics in Puerto Rico. J Assoc Nurses AIDS Care 2004; 15: 68-77.

18. Behravan H, Noghani M, Abachi A. Study the process of labeling for HIV patients (AIDS) and its implications (case study). Journal of Sociology of Iran 2011; 12: 1-16.

19. Nedjat S, Moazen B, Rezaei F, et al. Sexual and reproductive health needs of HIV-positive people in Tehran, Iran: a mixed-method descriptive study. Int J Health Policy Manag 2015; 4: 591-598.

20. Dessie Y, Deresa M. Sexual practices of HIV-positive individuals at tending antiretroviral treatment (ART) in Addis Ababa public hospitals: findings from in-depth interview. Pan Afr Med J 2012; 13: 80.

21. Ezeanolue EE, Wodi AP, Patel R, et al. Sexual behaviors and procreational intentions of adolescents and young adults with perinatally acquired human immunodeficiency virus infection: experience of an urban tertiary center. J Adolesc Health 2006; 38: 719-725.

22. Pearson CR, Cassels S, Kurth AE, et al. Change in sexual activity 12 months after ART initiation among HIV-positive Mozambicans. AIDS Behav 2011; 15: 778-787.

23. Bateganya M, Colfax G, Shafer LA, et al. Antiretroviral therapy and sexual behavior: a comparative study between antiretroviral-naive and-experienced patients at an urban HIV/AIDS care and research center in Kampala, Uganda. AIDS Patient Care STDS 2005; 19: 760-768.

24. Johnson P. Risky health behaviors and neurocognitive function among people living with HIV. University of Southern California, 2009.

25. Halkitis PN, Parsons JT, Wilton L. Barebacking among gay and bisexual men in New York City: explanations for the emergence of intentional unsafe behavior. Arch Sex Behav 2003; 32: 351-357.

26. Amoran O, Ladi-Akinyemi T. Sexual risk history and condom use among people living with HIV/AIDS in Ogun State, Nigeria. J Sex Med 2012; 9: 997-1004.

27. Sanders LB. Sexual behaviors and practices of women living with HIV in relation to pregnancy. J Assoc Nurs AIDS Care 2009; 20: 62-68.

28. Melchior R, Nemes MI, Alencar TM, Buchalla CM. Challenges of treatment adherence by people living with HIV/AIDS in Brazil. Rev Saude Publica 2007; 41 Suppl 2: 87-93.

29. Olalekan AW, Akintunde AR, Olatunji MV. Perception of societal stigma and discrimination towards people living with HIV/AIDS in Lagos, Nigeria: a qualitative study. Mater Sociomed 2014; 26: 191-194.

30. Mbalinda SN, Kiwanuka N, Kaye DK, Eriksson LE. Reproductive health and lifestyle factors associated with health-related quality of life among perinatally HIV-infected adolescents in Uganda. Health Qual Life Outcomes 2015; 13: 170.

31. Tufano CS, Amaral RA, Cardoso LR, Malbergier A, et al. The influence of depressive symptoms and substance use on adherence to antiretroviral therapy. A cross-sectional prevalence study. Sao Paulo Med J 2015; 133: 179-186.
32. Gaede BM, Majeke SJ, Modeste RR, et al. Social support and health behaviour in women living with HIV in KwaZulu-Natal. SAHARA J 2006; 3: 362-368.

33. Littlewood RA. Using 'common-sense'to understand complementary and alternative medicine use and HAART adherence in HIV+ people. Syracuse University, 2009.

34. Duggan J, Peterson WS, Schutz M, et al. Use of complementary and alternative therapies in $\mathrm{HIV}$-infected patients. AIDS Patient Care STDS 2001; 15: 159-167.

35. Uphold CR, Holmes W, Reid K, et al. Healthy lifestyles and health-related quality of life among men living with HIV infection. J Assoc Nurses AIDS Care 2007; 18: 54-66.

36. Orban LA, Stein R, Koenig LJ, et al. Coping strategies of adolescents living with HIV: disease-specific stressors and responses. AIDS Care 2010; 22: 420-430.

37. Mahmoudi M, Dehdari T, Shojaeezadeh D, Abbasian L. Coping with stress strategies in $\mathrm{HIV}$-infected Iranian patients. J Assoc Nurses AIDS Care 2015; 26: 464-471.

38. Sowell RL, Moneyham L, Guillory J, et al. Self-care activities of women infected with human immunodeficiency virus. Holist Nurs Pract 1997; 11: 18-26.

39. Vanable PA, Carey MP, Blair DC, Littlewood RA. Impact of HIV-related stigma on health behaviors and psychological adjustment among HIV-positive men and women. AIDS Behav 2006; 10: 473-482.

40. Plach SK, Stevens PE, Keigher S. Self-care of women growing older with HIV and/or AIDS. West J Nurs Res 2005; 27: 534-553.

41. Adedimeji AA, Alawode OO, Odutolu O. Impact of Care and Social Support on Wellbeing among people living with HIV/AIDS in Nigeria. Iran J Public Health 2010; 39: 30-38.

42. Salami AK, Fadeyi A, Ogunmodede JA, Desalu O. Factors influencing adherence to antiretroviral medication in Ilorin, Nigeria. J Int Assoc Physicians AIDS Care (Chic) 2010; 9: 191-195.

43. Bing EG, Burnam MA, Longshore D, et al. Psychiatric disorders and drug use among human immunodeficiency virus-infected adults in the United States. Arch Gen Psychiatry 2001; 58: 721 728.

44. Wang Y, Chen X, Li X et al. Cigarette smoking among Chinese PLWHA: An exploration of changes in smoking after being tested HIV positive. AIDS Care 2016; 28: 365-369.

45. Adeniyi OV, Ajayi AI, Selanto-Chairman N, et al. Demographic, clinical and behavioural determinants of HIV serostatus non-disclosure to sex partners among HIV-infected pregnant women in the eastern cape, South Africa. PLoS One 2017; 12: e0181730.

46. Parvin S, Eslamian A. The lived experience of women living with HIV in social relationships. Jurnal Women in Development and Politics 2014; 12: 207-228.

47. Sri Krishnan AK, Hendriksen E, Vallabhaneni S, et al. Sexual behaviors of individuals with HIV living in South India: a qualitative study. AIDS Educ Prev 2007; 19: 334-345.

48. Philogene J. Patterns of HIV serostatus disclosure among HIV-positive young adults in Haiti: A mixed methods investigation. Master's thesis, Duke University. Available at: http://hdl.handle.net/ 10161/8862. 2014.

49. Fallahi F, Tavafian S, Yaghmaie F, Hajizadeh E. Consequences of living with hiv/aids: A qualitative study. Journal of the Iranian Institute for Health Sciences Research (Payesh) 2013; 12: 243-253.

50. Abachi A, Behravan H. The Analysis of Stigma Impact on Quality of Life in Patients with HIV/AIDS: A Phenomenological Study. J Qual Res Health Sci 2013; 2: 158-172.

51. Peltzer K, Ramlagan S. Safer sexual behaviours after 1 year of antiretroviral treatment in KwaZulu-Natal, South Africa: a prospective cohort study. Sexual Health 2010; 7: 135-141.

52. van Servellen G, Lombardi E. Supportive relationships and medication adherence in HIV-infected, low-income Latinos. West J Nurs Res 2005; 27: 1023-1039. 
53. Li L, Lee SJ, Wen Y, et al. Antiretroviral therapy adherence among patients living with HIV/AIDS in Thailand. Nurs Health Sci 2010; 12: 212-220.

54. Radfar SR, Sedaghat A, Banihashemi AT, et al. Behaviors influencing human immunodeficiency virus transmission in the context of positive prevention among people living with HIV/acquired immunodeficiency syndrome in Iran: a qualitative study. Int J Prev Med 2014; 5: 976-983.

55. Kalichman SC. Understanding AIDS: Advances in research and treatment. American Psychological Association, 1998.

56. McGrath JW, Ankrah EM, Schumann DA, et al. AIDS and the urban family: its impact in Kampala, Uganda. AIDS Care 1993; 5: 55-70.

57. Esmaelzadeh Saeieh S, Ebadi A, Mahmoodi Z, et al. Barriers to disclosure of disease in HIV-infected women: a qualitative study. HIV AIDS Rev 2018; 17: 12-17.

58. Zhang Y, Zhang X, Aleong TH, et al. Impact of HIV/AIDS on social relationships in rural China. Open AIDS J 2011; 5: 67-73.

59. Lekganyane R, du Plessis G. Dealing with HIV-related stigma: a qualitative study of women outpatients from the Chris Hani Baragwanath Hospital. J Assoc Nurses AIDS Care 2012; 23: 155 162.

60. Tavakol M, Nikaeen D. The stigmatization of patient physician relationship and treatment in patients with HIV/AIDS. Biological Ethics Quarterly 2012; 2: 11-43.

61. Gostin LO. The AIDS litigation project: a national review of court and human rights commission decisions, Part II: Discrimination. JAMA 1990; 263: 2086-2093.

62. Kabbash IA, El-Gueneidy M, Sharaf AY, et al. Needs assessment and coping strategies of persons infected with HIV in Egypt. Eastern Mediterranean Health Journal 2008; 14: 1308-1320.

63. Behboodi-Moghadam Z, Esmaelzadeh-Saeieh S, Ebadi A, et al. Development and psychometric evaluation of a reproductive health assessment scale for HIV-positive women. Shiraz E Medical Journal 2016; 17: e38489.

64. Yang MH, Chen YM, Kuo BI, Wang KY. Quality of life and related factors for people living with HIV/AIDS in Northern Taiwan. J Nurs Res 2003; 11: 217-226.

65. Radzniwan R, Alyani M, Aida J, et al. Psychological status and its clinical determinants among people living with HIV/AIDS (PLWHA) in Northern Peninsular Malaysia. HIV AIDS Rev 2016; 15: 141-146. 